\title{
Drilling Library: A Modelica library for the simulation of well construction
}

\author{
Reza Dadfar $^{1} \quad$ Stéphane Velut $^{1} \quad$ Per-Ola Larsson $^{1}$ \\ Mathias Strandberg $^{1} \quad$ Håkan Runvik $^{1} \quad$ Johan Wíndahl $^{1}$ \\ Pål Kittilsen ${ }^{2} \quad$ John-Morten Godhavn ${ }^{2} \quad$ Åsmund Hjulstad ${ }^{2}$ \\ ${ }^{1}$ Modelon, Sweden, \{reza.dadfar, stephane.velut, per-ola.larsson, \\ mathias.strandberg, hakan.runvik, johan.windahl\}@modelon.com \\ ${ }^{2}$ Equinor, Norway, \{pkit, jmgo, ahju\}@equinor.com
}

\begin{abstract}
A Modelica library for the simulation of well construction (drilling) is presented in this paper. The library contains most of the components of a drilling system. The simulation model is capable to capture the main dynamics of the well, including the hydraulics, the mud transport, the mechanics of the drill string as well as the drill bit interaction with the bore hole. The library is well suited to simulate the well operation and to support the development of new technologies. The modelling assumptions of the library's components are first reviewed. Subsequently, an experiment is performed to test the rotational and translational frictions.
\end{abstract}

Keywords: Drilling library, fluid-structure interaction, well construction, borehole, surge and swab, mud, Modelica.

\section{Introduction}

The cost of oil and gas production includes exploration, well and facility construction, operation and cessation. Among all, well construction makes up a considerable part of the cost.

A variety of parties contribute to the well construction, i.e. the oil company, the owner of the drilling rig, the rig-building yard, manufacturers of drilling equipment, and companies that provide equipment and services during the drilling operation. Their relative roles have been refined over years and is not easily changeable. The opportunities from new technologies may require small modifications in the contribution of several parties and is difficult to achieve considering commercially and timewise detachment players. The larger changes that major players can realize may require significant changes to roles and responsibilities (de Wardt, 2014).

However, once benefit is shown, changes are more achievable. In this regard, modeling and simulation can be used as a shared language which may facilitate the cooperation between the actors.
The multitude of simulation tools in the well construction is specialized for developing and validating well designs, and not for developing new technologies. The relevant questions are more of the type: "Is this steel pipe good enough?" as opposed to "what behavior will this system exhibit?". The tools are often discipline specific, vendor proprietary and with few or no extension interfaces for combining results. In addition, there is still a clear disconnection between the simulation tools for downhole processes and topside automation.

Larger changes in the construction methods have the subsequent structural changes in simulation tools. This may be difficult to achieve in the mature commercial tools.

Well construction is typically divided into two phases: drilling and completion. The well is drilled in sections. First a wide hole (13"-30") is drilled a few hundred meters down. The borehole wall is secured by running casing, an open-ended steel cylinder, the same length as the drilled hole. The bottom end, both the annular space outside the casing and inside the casing, is filled with cement. A smaller hole is then drilled through the cement and continuing further towards the target. The steps are repeated until a 3"-9" hole is drilled in the target reservoir, preferably along several hundred meters of hydrocarbon-filled rock, some thousand meters away from the start.

Drilling fluids are pumped through the drill pipe and up to the annulus to transport drilled cuttings out of the hole, to cool down the equipment and to stop formation fluids from uncontrolled flow into the well.

During the completion phase, various equipment is installed to make the well ready for production. The type of completion equipment varies significantly, from a very simple open hole to wells equipped with sensors, pumps, flow control devices, chemical injection lines, gas lift, etc. 
The modeling of the well construction involves a lot of challenges. The modelling domains (flow circulation, rotation and translation of drill pipe) are physically coupled both along the drill-string and near the bit. The thermal energy domain contains convection-driven flow (along the flow path), radial diffusion (between drill string and surrounding rock), and variable fluid composition. The fluid is non-Newtonian and the rheological properties depends on time and temperature. We should not try to always deal with all these effects simultaneously. For many problems, it is more appropriate to select relevant physical phenomena and system components. This is where Modelica may prove useful (Fritzson, 2014).

In the following, some industrial applications are listed as examples of new technologies or components where understanding of the dynamics of physical processes is important for both overall system and control system design. The development includes significant modelling and simulation work. In some cases, it may have been necessary to develop simulation models from scratch. A language like Modelica and a shared base of libraries may reduce the simulation costs, decrease the threshold to use dynamic simulation (i.e. in research, concept development, engineering and testing), and may make it easier to include custom components in simulated demonstration, operations preparations or training.

The following examples are not indication of Modelica use (known to the authors), but rather recent technology developments of a kind that would benefit from a general and flexible drilling library.

1. Maintaining downhole pressure within desired limits during drilling operations is a well-studied problem. Industrial solutions exist and is referred to as Managed Pressure Drilling (Chin, 2012). The following are some examples:

a) On Norwegian continental shelf, the first offshore applications are described in (Bjørkevoll et. al., 2008), (Eck-Olsen et. al., 2005), where rich models are used as input to automatic choke control. Kaasa et.al, (Kaasa et. al., 2012) argue for using a simplified process model in design of estimation and control algorithms and for reducing the complexity and footprint of the control system software. Both approaches still use a top-side choke for pressure control, and neither solve issues that arise when drilling from floating installations; heaveinduced downhole pressure oscillations.

b) Another approach is to use a downhole valve to reduce the pressure oscillations (Kvernland, 2018).

c) For deep water, a reduced liquid level in the drilling riser (as opposed to increased backpressure topside) is used to control downhole pressure. Various alternatives exist (Godhavn, 2014) with subsea pumps, in combination with sealing devices and valves.

d) Conventionally, the fluid flows downwards inside the drill pipe, returning to the annular outside space. An idea is to use a drill pipe with two concentric channels, with return flow inside the pipe, (Aleksandersen et. al., 2015).

2. A similar application is automatic well control solutions, where the task is to first detect a kick/influx, then stop the influx and finally handle the influx by circulating it out using well control equipment. The flow in the annulus is multiphase and contains drilling fluid, rock particles and possibly gas from formation influx.

3. An additional application example that would benefit from a flexible drilling library are drill-string vibration (detection and handling).

4. Automatic mud mixing is another example. Drilling mud is designed with several properties, where density and viscosity are the most important properties. Maintaining and controlling these properties are very important. Simulating the mud properties through the topside process as well as the drill pipe and the annulus may be a challenge as the properties are changing with time, pressure and temperature.

These are examples of new types of equipment and changes in model structure that are not easily implementable in typical simulation software when conceiving the idea. The drilling library presented in the current paper is the first version of that versatile tool that aims at supporting the development of new technologies for drilling processes. Simulation models could ultimately be used as knowledge carriers between the parties involved in the well construction or as digital twin to monitor the well operation.

\section{Drilling Library}

The simulation of the drilling operation using a flexible tool makes it possible to obtain a realistic behavior of the operation, graphical representation of the results, sensitivity analyses and control design. In the modern, high pressure and high temperature, HPHT, wells, it is crucial to have a profound understanding of the dynamic behavior of the well for accurate well planning, training and operational assistance. In this regard, Modelica is a well-known tool providing a flexible platform to simulate multi domain physics including the thermoflow and mechanical dynamics. Hence it is well suited for the simulation of the drilling operation and control.

The aim is to build a library to simulate: 
1. Well hydraulics: From the main pump at the surface to the topside interface.

2. Drill string mechanics:

- Detailed mechanics of the string (torsion and elongation)

- Rotational friction between string and surrounding fluids

- Interaction of the drill bit with the surroundings to describe the bore hole growth

3. Mud transport: The transported fluid that is normally a mixture of oil, water and granular particles.

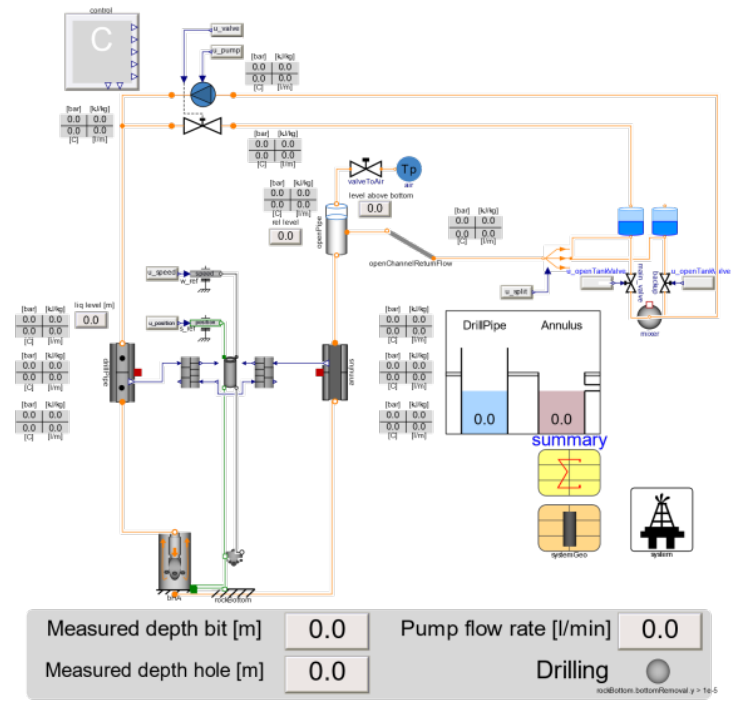

Figure 1. Modelica model of a drilling system

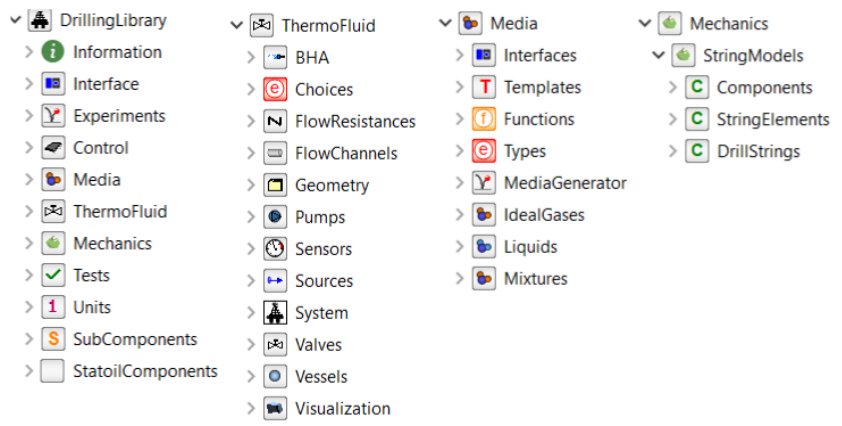

Figure 2. Overview of the Modelica drilling library

The current library illustrated in Figure 1 and in Figure 2 is organized in packages;

1. Media package: for the state equations and transport properties that defines the physical properties of the drilling fluid i.e. mud.

2. Thermal package for the thermofluid components used in the hydraulic and thermal modeling of the drilling operation.
3. Mechanics package for the mechanical parts of the system including the drill string and the mechanical friction correlations.

4. Control package: contains all the control blocks required to operate the entire drilling operations.

5. Experiments package: contains the system models, where different scenarios using mechanical and thermo-fluid components can be built based on a template.

\subsection{Media package}

In this package the medium properties of the drilling fluid are implemented. The medium properties depend on temperature $\mathrm{T}$, pressure $\mathrm{p}$ and mass fraction $\mathrm{X}$;

$$
\begin{aligned}
& \rho=\rho(p, T, X) \\
& h=h(p, T, X) \\
& \mu=\mu(p, T, X)
\end{aligned}
$$

where $\rho, h, \mu$ are density, specific enthalpy and dynamic viscosity, respectively.

The drilling fluid is made of five components, namely

- Two solid constituents: low and high gravity granular particles

- Two liquid constituents: base oil and brine

- One gas.

The gas is treated as an ideal gas; the properties of the solid particles are constant; and the liquids are governed by a bilinear equation of state:

$$
\begin{gathered}
d \rho_{k}=\left(\frac{\partial \rho_{k}}{\partial p}\right)_{T} d p+\left(\frac{\partial \rho_{k}}{\partial T}\right)_{p} d T \\
+\left(\frac{\partial^{2} \rho_{k}}{\partial p \partial T}\right)_{p T} d T d p
\end{gathered}
$$

$$
\begin{gathered}
\left(\frac{\partial \rho_{k}}{\partial T}\right)_{p}=-\rho_{0, k} \alpha_{k} \\
\left(\frac{\partial \rho_{k}}{\partial p}\right)_{T}=\frac{\rho_{0, k}}{\beta_{k}}
\end{gathered}
$$

where $k=$ base oil and brine, respectively.

The specific enthalpy of the liquids was assumed to depend only on temperature and composition, i.e. $h=$ $h(T, X)$. The implementation can be easily extended to include pressure dependency $h=h(p, T, X)$. The mud mixture properties are finally obtained as

$$
\begin{gathered}
1 / \rho=\sum_{i=1}^{n} X_{i} / \rho_{i} \\
h=h_{r e f}+\sum_{i=1}^{n} c_{p, i} X_{i}\left(T-T_{r e f}\right) \\
\mu=\mu_{0} 10^{\frac{\mu_{1}}{T-T_{0}}}
\end{gathered}
$$

where $c_{p, i}, \mu_{0}, \mu_{1}, T_{0}, h_{r e f}, T_{r e f}$ are constants, and $i=$ $1, \ldots n$; where $n$ is the number of components. 


\subsection{Thermal Package}

This package contains a hierarchical component structure used in the thermo-fluid subsystems. This domain communicates with the mechanical domain through appropriate interface (see 2.3).

\subsubsection{Flow channels}

The flow channel describes the flow through the drill string and the annulus (Figure 3 and Figure 4). The component model is implemented by combining two approaches:

The first approach is a finite volume discretization on a staggered grid where the mass and energy balance are implemented in a dynamic volume and the momentum equation is modeled in a flow resistance/static head component. This component is keeping track in a dynamic fashion of the pressure, the enthalpy and the composition in the bore hole.

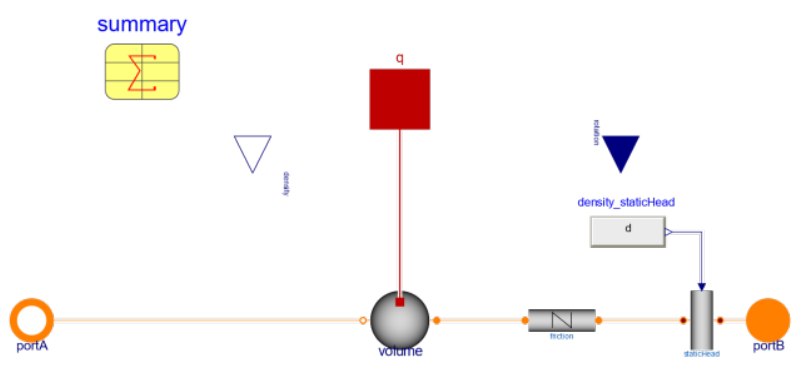

Figure 3. Modelica model of a pipe segment, implemented as the serial connection of a control volume, a friction loss model and a static head computation

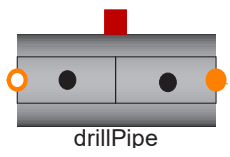

Figure 4. Drill pipe component implemented as a series of pipe segments

The balance equations read:

$$
\begin{gathered}
\frac{\partial h}{d t}+\left(\frac{\dot{m}}{\rho A}\right) \frac{\partial h}{\partial x}-\frac{1}{\rho} \frac{d p}{d t}-\frac{P}{\rho A} q^{\prime \prime}=0 \\
\frac{\partial p}{\partial x}+\rho g \frac{\partial z}{\partial x}+\frac{\partial \tau_{w}}{\partial x}=0 \\
A \frac{\partial \rho}{\partial t}+\frac{\partial \dot{m}}{\partial x}=0 \\
A \frac{\partial \rho X_{i}}{\partial t}+\frac{\partial \dot{m} X_{i}}{\partial x}=0
\end{gathered}
$$

where $X_{i}$ is the mass fraction for each component, $i=$ $1, \ldots, n$, and $\dot{m}, \tau_{w}, A, P, q^{\prime \prime}$ are mass flow rate, wall shear stress, pipe cross section area, pipe wetted perimeter and heat flux, respectively. In the momentum equations, the unsteady and convection terms, and in the energy equation, the conduction and the viscous dissipation terms are not considered.
The Modelica built-in operator "spatial distribution" is used in parallel with the finite volume channel to model the transport of the solid particles without any numerical diffusion and to increase the robustness and the speed of the simulation. This operator approximates the solution of the plug-flow partial differential equation in a robust way. The operator supports reverse flow and keeps track of the spatial distribution of the quantity, when the flow varies via sampling, interpolation and shifting of the previous distribution (Fritzson, 2014). The species balance can then be re-written in a form that is suitable for the spatial distribution operator:

$$
\begin{aligned}
& \frac{d X_{i}}{d t}+u \frac{d X_{i}}{d x}=0 \\
& X_{i}(0, t)=X_{i, A} \\
& X_{i}(L, t)=X_{i, B}
\end{aligned}
$$

The species' mass fraction returned by the spatial distribution operator is passed to the control volume to be used in the species balances therein. The velocity that is sent to the spatial distribution operator is computed as follows;

$$
u(t)=\frac{\dot{m}_{A}+\dot{m}_{B}}{2 \rho},
$$

where $\mathrm{A}$ and $\mathrm{B}$ are the boundaries of the control volume.

\subsubsection{Flow resistances}

The pressure loss has to be estimated for each component in the mud circulation system. To obtain the pressure loss in the drill pipe and annulus, wall friction is estimated as

$$
\frac{\partial \tau_{w}}{\partial x}=\frac{2 f}{\rho D_{h} A^{2}} \dot{m}|\dot{m}|,
$$

where $f$ is the fanning friction factor and $D_{h}$ is the hydraulic diameter of the pipe. The friction factor $f$ is determined, depending on the selected friction correlation. For this library two correlations are provided, i.e. Herschel-Bulkley and Power-Law (Zamora et. al. , 2002) and (Zamora et. al. 2005).

In the drill bit and bottom hole assembly, the pressure loss is determined as

$$
\begin{aligned}
\Delta p_{b i t} & =\frac{1}{2 \rho\left(c_{v} A\right)^{2}} \dot{m}|\dot{m}| \\
\Delta p_{b h a} & =\frac{c_{d t}}{\rho_{d t}} \rho^{0.86} \dot{m}|\dot{m}|^{0.86}
\end{aligned}
$$

where $c_{v}, c_{d t}, \rho_{d t}$ are the discharge coefficient, pressure coefficient for down-hole tool and reference fluid density, respectively.

\subsubsection{Bottom hole assembly}

The length of the wellbore increases during drilling. This effect is modelled in the fluid system by a variable volume component located between the drill bit and 
bottom hole assembly. The volume is estimated based on the drilling string displacement. The interaction is modeled by two flange ports as shown in Figure 5. As a part of fluid-mechanic interaction, the fluid system introduces an equivalent force on the drill string;

$$
F=p_{b h a} A_{b i t}
$$

The fluid system provides also the information of densities in the drill string and annulus and hand it over to mechanics to determine the buoyancy force.

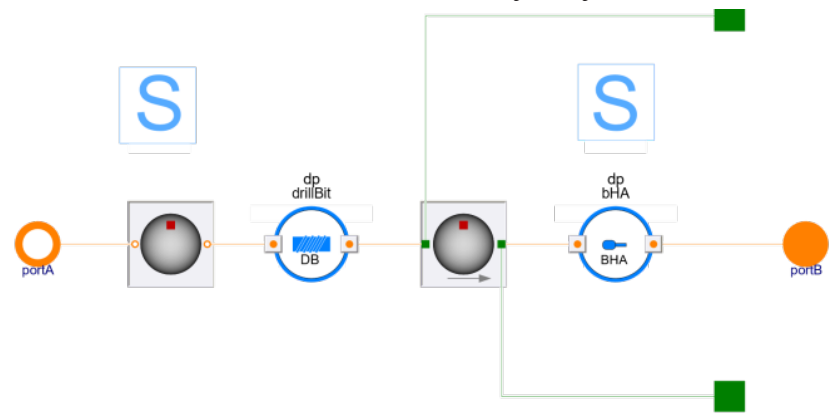

Figure 5. Modelica model of the bottom hole assembly and drill bit.

\subsubsection{Vessels}

Two open tanks are considered in this system. Each tank contains different mud compositions. Hence the density of the circulating mud can be controlled by using mud from each or the combination of two tanks.

In the mud circulating system, the top of annulus opens to the atmosphere. To model this, "open pipe" is added to the top of the annulus. This model is connected to the return line through a third fluid port. The free surface level is estimated, and the result is visualized graphically.

\subsection{Mechanics Package}

The Mechanics package includes models covering the drill string and its mechanical interaction with the well bottom and the annulus. The drill string also interfaces to the fluid. The string is assumed rotating only around its own axis and does not include eccentricity. It's also assumed hanging free in completely vertical parts of the well and resting on the bottom of the well in parts with inclination.

\subsubsection{Drill-string}

The drill string was implemented using a lumped mass approach, where each segment of the string has 2 degrees of freedom, one translational and one rotational, defined along the well trajectory. The drill string is assembled by a number of these elements and their interactions.

\subsubsection{Elements}

Each element consists of two masses connected with one spring damper element. The masses are calculated from geometric input, the inner radius $\left(r_{\text {inner }}\right)$, the outer radius $\left(r_{\text {outer }}\right)$, Length, $\rho$, Young's modulus $(E)$, shear modulus $(G)$. The spring stiffness is calculated so that with a given force or torque, the static deformation of the element is correct. The elements also contain a damping factor, that is currently overestimated, which leads to more damping of rotational and translational oscillations. More work is needed to estimate effects and improve the damping effects in the system.

\subsubsection{Buoyancy and gravity}

Each element has access to its current position along the well trajectory and can acquire information about the local fluid densities inside the string and annulus, and the well inclination. With this information the correct buoyancy effect can be calculated. The buoyance has an effect on the normal force between the string and annulus. This will also calculate the gravitational effect along the string.

\subsubsection{Friction}

The friction applied in the contact is a $2 \mathrm{~d}$ model defining a force ellipse for break- away friction. This enables the study of the connected effects of rotational and translational friction. Typical example is when the string is twisted but at rest in the well, and the string is pulled out, the friction is saturated by the translational motion and at one point the rotational friction cannot hold the twisted string and unwinds.

The friction model is parameterized using a table providing Coulomb and viscous friction coefficients as function of temperature.

\subsubsection{Bottom removal}

The bottom removal model is designed to remove mass and increase well depth of the system. It consists of a contact model, initialized at the defined start depth of the well, and a removal model. The removal model defines a relationship between bit rotational speed, contact force and gives the penetration speed. This speed is then applied to the bottom contact and moves it further down along the predefined well trajectory data.

\subsubsection{Experiments}

Several Modelica experiments have been implemented using reconfigurable system templates provided in the library. The aim was to assess the behavior of the drilling system and of the library components under various conditions with respect to both the mechanical and the fluid domains. Experiments in the fluid domain included switching on and off the mud pump and tracking the pressure and flow along the string and through the bit; adding solid particles and tracking the front propagation; surge and swab scenarios. As far as the mechanical sub-system is concerned, both rotational and translational friction tests were conducted. The latter is explained in more details in this section.

During drilling long wells, especially with nearhorizonal trajectories, it is important to monitor 
translational and rotational friction between drillstring and borehole. Deviation from expected behavior causes difficulties under development (Johancsik et. al., 1984). It can lead to poor hole-cleaning performance (drilled rock is not being transported out) and well path tortuosity (Skillingstad et. al., 2000). Automatic execution of friction tests has recently been applied to offshore operations. Standardization of the test procedure and using software to compensate for variations in test execution are important for accurate results (Cayeux et. al., 2017).

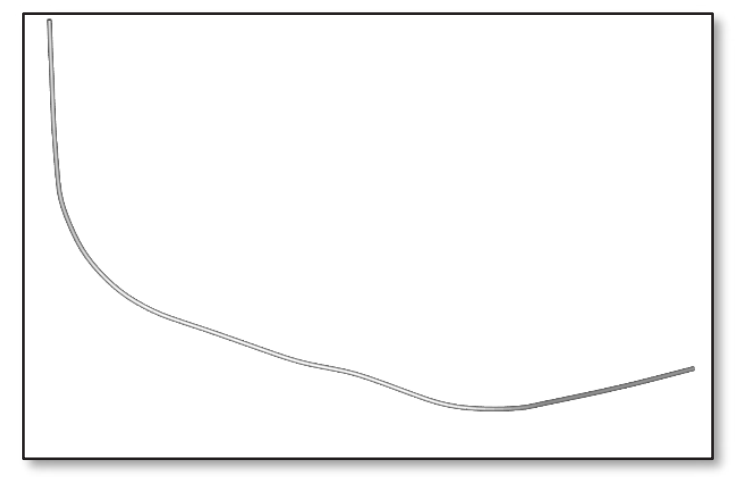

Figure 6. Three-dimensional well trajectory

The trajectory of the well is shown in Figure 6. The geometrical data of the well are propagated to both the thermo-fluid and mechanics sub systems.

The test is performed by controlling the movement of the top block (see Figure 7). The drilling operation is performed up to $t=80 \mathrm{~s}$. Then, the block stops its vertical descent and let the drill-bit to drill off the bottom.

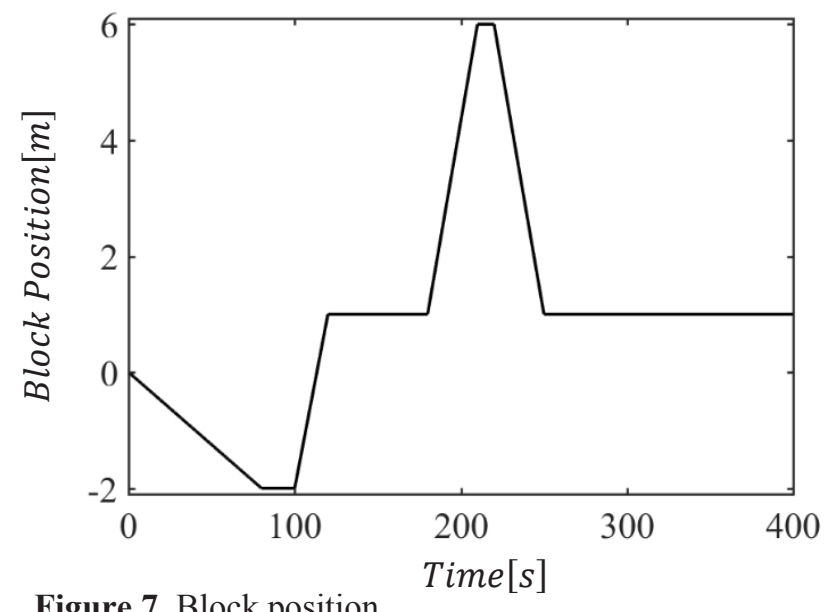

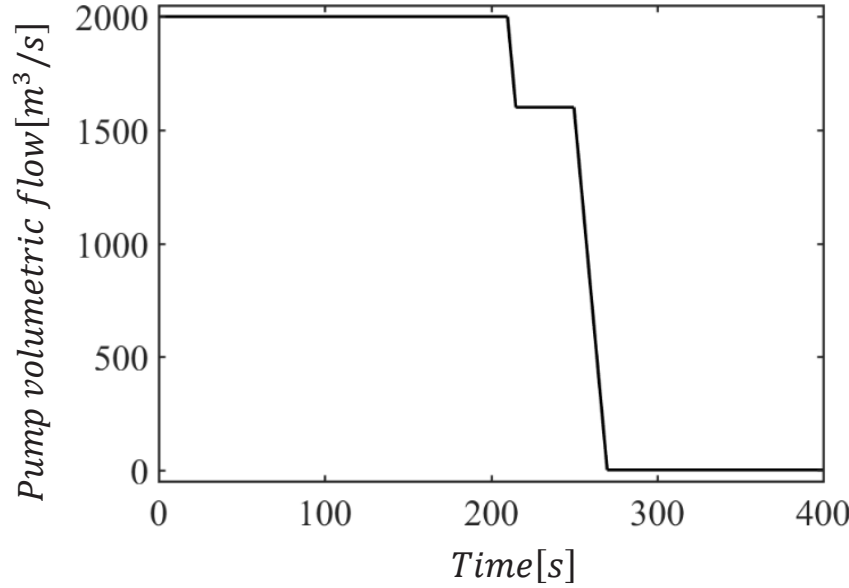

Figure 8. pump volumetric flow

At $\mathrm{t}=100 \mathrm{~s}$, the string is pulled up $3 \mathrm{~m}$ for $20 \mathrm{~s}$, where the top block stops the rotation of the drill string. Then, the string is pulled up and pushed down for $5 \mathrm{~m}$ to measure the hook force and to estimate the friction along the well. The friction estimation was not actually performed in this example.

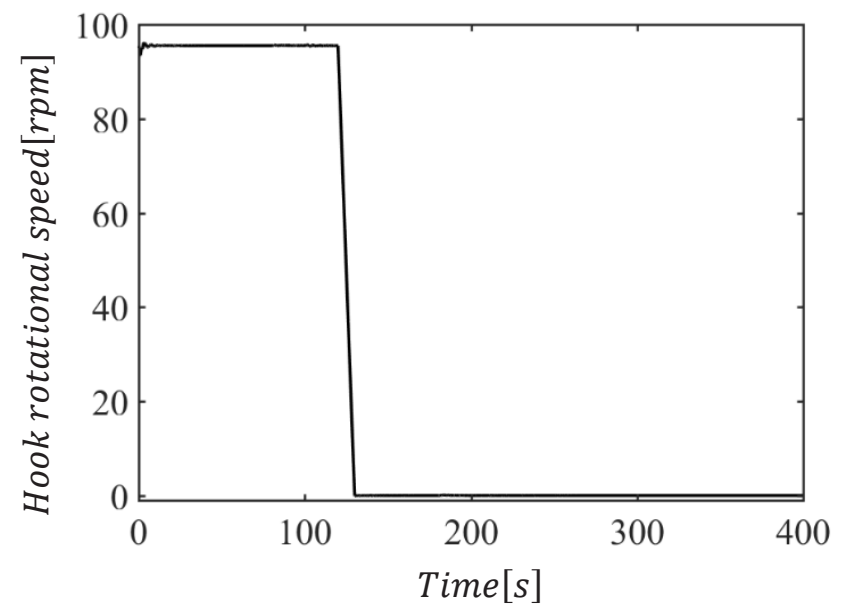

Figure 9. Hook rotational speed

Then, the string is pulled up and pushed down for $5 \mathrm{~m}$ to measure the hook force and to estimate the friction along the well. The friction estimation was not actually performed in this example. Block position, pump volumetric flow and the hook rotational speed are shown in Figure 7, Figure 8 and Figure 9.

Initial transients in the bit rotational speed is shown in Figure 10. The transient is because the string starts with zero twist, and the initial rotations starts to twist the string, successively overcoming the friction force and then the bit starts to rotate. 


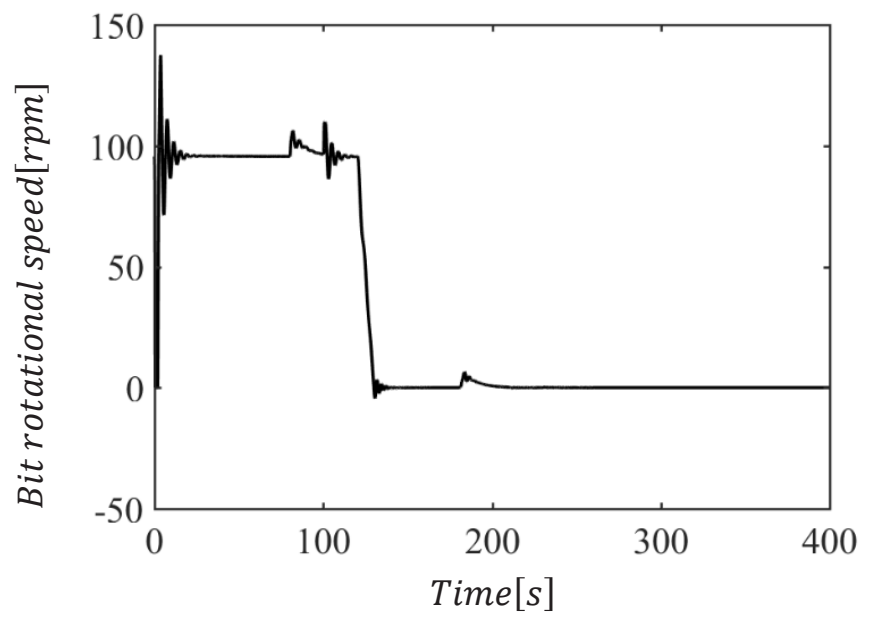

Figure 10. Bit rotational speed

Contact force in the bottom is shown in Figure 11. The force decays at $\mathrm{t}=80 \mathrm{~s}$ then the bit drills off the bottom.

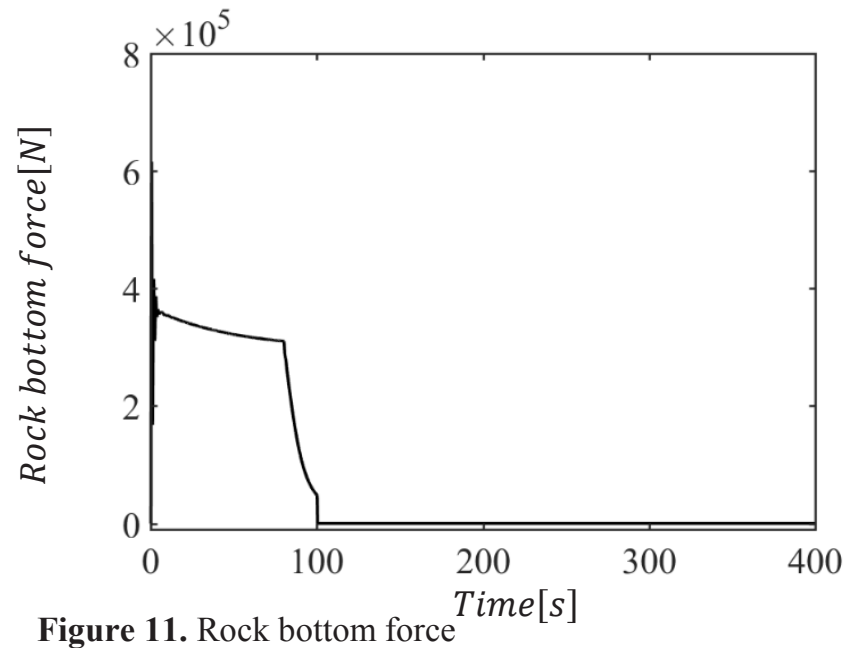

The difference in bit and hook torque are shown in Figure 12. When the bit is off the bottom, the reaction torques decreases, and the bit torque is reduced to zero. The drill string is still twisted and stuck because of the friction. This reaction torque can be seen in the hook torque.

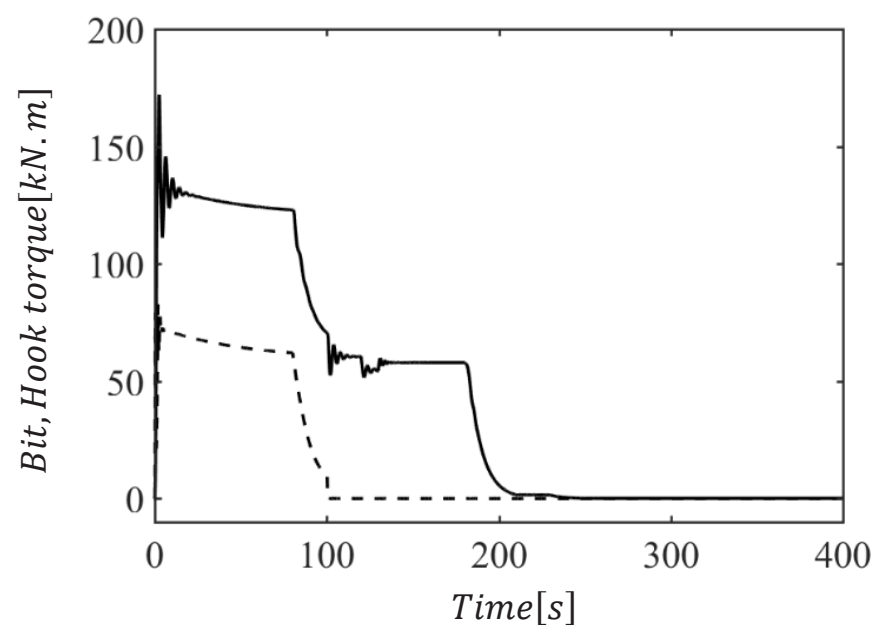

Figure 12. Bit and Hook torque; the solid line represent the hook torque while the dotted line shows the bit torque
When the string is pulled up at $t=180 \mathrm{~s}$, the friction is saturated because of the axial translational movement and it can no longer resist the twist and unwinds.

\section{Conclusions and outlook}

The drilling library presented in the current paper is a first step towards a versatile tool for new technology development for well construction. It shows the potential of the Modelica technology in a simple but quite complete drilling system with fluid-mechanical interactions. The chosen implementation strategies show computation times that are suitable for interactive work. In Equinor, Modelica is used for control studies and design within oil and gas production and processing, and also as a tool to produce FMUs for integration in process simulators. The modularity and extensibility of Modelica is expected to lower the threshold for using dynamic simulation in prototyping systems and control functions for well construction. The proposed library is currently planned to be used by Equinor within research work and in cooperation with academia. The authors welcome also industrial partners to participate in the further development of the library.

\section{References}

Aleksandersen, J., \& Vestavik, O. M. (2015). Dual-Drillpipe Method Shows Success in PMCD Wells With Cuttings Return. Journal of Petroleum Technology, 67, 32-35. doi:10.2118/0415-0032-JPT

Bjørkevoll, K. S., Molde, D. O., Rommetveit, R., \& Syltoy, S. (2008). MPD operation solved drilling challenges in a severely depleted HP/HT reservoir. IADC/SPE Drilling Conference. doi:10.2118/112739-MS

Cayeux, E., Skadsem, H. J., Daireaux, B., \& Holand, R. (2017). Challenges and solutions to the correct interpretation of drilling friction tests. SPE/IADC Drilling Conference and Exhibition. doi:10.2118/184657-MS

Chin, W. C. (2012). Managed pressure drilling: modeling, strategy and planning. Gulf Professional Publishing.

de Wardt, J. (2014). The drilling business model: driver or inhibitor of performance and innovation. IADC/SPE Drilling Conference and Exhibition. doi:https://doi.org/10.2118/167933-MS

Eck-Olsen, J., Pettersen, P.-J., Ronneberg, A., Bjørkevoll, K. S., \& Rommetveit, R. (2005). Managing pressures during underbalanced cementing by chok ing the return flow; innovative design and operational modeling as well as operational lessons. SPE/IADC Drilling Conference. doi:10.2118/92568-MS

Fritzson, P. (2014). Principles of object-oriented modeling and simulation with Modelica 3.3: a cyber-physical approach. John Wiley \& Sons.

Gerogiorgis, D. I. (2006). Dynamic oil and gas production optimization via explicit reservoir simulation. Computer 
Aided Chemical Engineering, 21, 179-184. doi:10.1016/S1570-7946(06)80043-X

Godhavn, J.-M., Hauge, E., Molde, D. O., Kjøsnes, I., Gaassand, S., Fossli, S. B., \& Stave, R. (2014). ECD Management Toolbox for Floating Drilling Units. Offshore Technology Conference. doi:10.4043/25292-MS

Johancsik, C. A., Friesen, D. B., \& Dawson, R. (1984). Torque and drag in directional wells-prediction and measurement. Journal of Petroleum Technology, 36, 987-992. doi:10.2118/11380-PA

Kaasa, G.-O., Stamnes, Ø. N., Aamo, O. M., \& Imsland, L. S. (2012). Simplified hydraulics model used for intelligent estimation of downhole pressure for a managed-pressuredrilling control system. SPE Drilling \& Completion, 27, 127-138. doi:10.2118/143097-PA

Kvernland, M., Christensen, M. Ø., Borgen, H., Godhavn, J.M., Aamo, O. M., \& Sangesland, S. (2018). Attenuating Heave-Induced Pressure Oscillations using Automated Down-hole Choking. IADC/SPE Drilling Conference and Exhibition. doi:10.2118/189657-MS

Skillingstad, T. (2000). At-bit inclination measurements improves directional drilling efficiency and control. IADC/SPE Drilling Conference. doi:10.2118/59194-MS

Zamora, M., \& Power, D. (2002). Making a case for AADE hydraulics and the unified rheological model. AADE 2002 Technology Conference Drilling \& Completion Fluids and Waste Management, Houston, USA.

Zamora, M., Roy, S., \& Slater, K. (2005). Comparing a basic set of drilling fluid pressure-loss relationships to flow-loop and field data. AADE 2005 National Technical Conference and Exhibition, (ss. 5-7). 